\title{
LANGUAGE AND PRIMING MEMORY
}

\author{
Marcus Maia*
}

ABSTRACT: This article provides an overview on the notion of priming memory and its use in psycholinguistic research. The literature in the areas of word recognition and sentence processing is briefly reviewed and a psycholinguistic experiment conducted by the author in order to investigate the comprehension of object anaphora in Brazilian Portuguese is reported.

KEY WORDS: Priming memory, word recognition, sentence processing, null objects

\section{INTRODUCTION}

The concepts of activation and priming are powerful instruments for describing psycholinguistic processes. The notion of activation has not only provided a framework in order to interpret experimental results in the areas of word recognition, sentence and discourse processing, but it is also one of the leading ideas informing connectionist models ${ }^{1}$. The objective of this article is twofold: to outline some of the important components of a theory of activation and priming as they have been established in studies dealing with word recognition and sentence and discourse processing and to demonstrate the relevance of the general theory of priming and activation in the investigation of a specific case, namely, the comprehension of object anaphora in Brazilian Portuguese. The article is organized as follows: section 1 will briefly review the literature on priming studies in the area of word recognition; section 2 will outline studies which investigate priming memory in the area of sentence processing; section 2.1 will provide an overview on studies concerning the perceptual reality of coreference assignment; section 2.2 will address issues concerning decision principles and constraints on information use in the comprehension of sentences. Finally, section 3 will describe and analyze a psycholinguistic experiment entirely based on the concept of priming memory which was conducted by the author (Maia, 1994) in order to assess the psychological reality of the empty category in object position.in Brazilian Portuguese.

* Museu Nacional - Universidade Federal do Rio de Janeiro/CNPq.

1 A full-fledged theory of activation is substantiated, for example, in the parallel distributed processing approach described by McClelland, St. John, and Taraban (1989). 


\section{PRIMING MEMORY IN WORD RECOGNITION}

Priming is a nonconscious form of implicit human memory, which is concerned with perceptual identification of words and objects. According to Tulving and Schacter (1990), the prototypical priming experiment consists of two stages. In the first stage, the subject is presented with a stimulus object, for example a word. In the second stage, a reduced cue or an associated stimulus is presented for recognition (for example, a word wich is semantically or phonologically related to the first word). Priming is said to have been demonstrated if the probability of the identification of the previously encountered targets is increased, or the latency of the identification response is reduced, in comparison with similar measures for nonstudied control items. The difference between performance on the target items and the nonstudied items provides a measure of the magnitude of the priming effect.

Priming is possible at all, because cognitive units in memory can be thought of as varying in its level of activation. From its resting level of activation, a unit may be activated as a result of perceptual and/or linguistic processing. For example, the concept "JELLY" can become active if one sees some jelly, or hears the word jelly (Anderson, 1983). To say that a concept has been activated has been interpreted in the literature as meaning that it has been brought into short-term or working memory. Actually, it is interesting to notice that the concept of activation provides one definition of working memory itself, since working memory has been defined as the system of memory which is occupied by active information (Singer, 1990:10).

Kintsch and Vipond (1979) propose that not only the concept, but also the proposition that contains the concept is brought into working memory. This means that activation spreads in propositional networks, from active concepts to related ideas. Different semantic priming studies have established the notion of automatic spreading activation by showing that the processing of a word is influenced by the words presented before it. This preactivation effect on the listener's attention is based on the assumption that if a word facilitates the processing of another the two are likely to be closely connected. Thus semantic priming has been used in order to investigate different models of lexical access, memory organization, and sentence processing.

The methodology in these studies has often included word lists and used the lexical decision task. Typically, the basic procedure involved measuring how fast subjects can decide whether or not a string of letters is a word. For example, in a classic study, Meyer and Schvaneveldt (1971) presented to subjects strings of letters grouped into five types of pairs, one of which contained associated words such as bread-butter or nurse-doctor, another contained unassociated words such as nurse-butter or bread-doctor. Other three groups were formed by word-nonword, nonword-word and nonword-nonword. Subjects were asked to judge whether or not each string of letters in the pairs was a word by pressing a yes or no key. 
Reaction times were measured separately for each string from the stimulus onset to the keypress. Their results indicated that correct judgment time for a word string is faster when it immediately follows a related word than when it immediately follows an unrelated one.

Meyer, Schvaneveldt and Ruddy (1974) also found out that the way a word sounds affects lexical access. They asked subjects to perform simultaneous lexical decisions on pairs of visually similar words that sounded either the same, for example set/wet, or different, for instance, few / sew. The decisions for the rhyming pair were faster, indicating that the lexicon is organized in terms of sound.

In another experiment, Meyer, Schvaneveldt and Ruddy (1975) compared data from the lexical decision task with subjects' performance on a pronunciation task. In this study subjects vocalized strings of letters, rather than classifying them as words or nonwords. The design of the pronunciation task was similar to the lexical-decision task and followed the general structure of the experiment described above. Subjects had to judge whether or not the first string of letters in each stimulus pair was a word, pressing one of two finger keys to indicate his decision. However their responses differed for the second string, since subjects were asked to pronounce the string, regardless whether it was a word or a nonword. Again significant effects of semantic context were found: mean reaction times of correct vocal responses to the second word were faster in associated pairs than in unassociated pairs. These results were interpreted by the authors as an indication that semantic context may influence an early stage of visual word-recognition in which strings of letters are encoded graphemically and transformed to phonemic representations used for accessing lexical memory.

Another closely related issue that seems to have been a topic of discussion in the literature is the fact that the spread of activation can also be controlled. In order to demonstrate this issue, Neely (1977) designed a study in which subjects were presented category names such as bird, building or body. Then they had to make a lexical decision about a letter string. Besides presenting association between categories and their instances, such as bird and robin, Neely also presented what he called "cognitive" associations, by telling subjects beforehand that whenever the word building appeared, they should focus their attention on the category of body parts, and vice versa. Under these conditions, subjects needed less time to judge that elbow or arm are words when preceded by the category name building than when it was preceded by the neutral cue, XXXXX. In other words, the subjects controlled the spread of activation from the concept building to the category of body parts. Neely also varied the time between the presentation of the two words, so that the time-course of facilitory and inhibitory effects could also be investigated. With the category-instance associations the facilitation began to act very promptly, while all the other effects were comparatively slow. He identified the automatic and the controlled spread of activation respectively with the automatic and conscious processes postulated in studies of attentional processes by Posner and Snyder (1975). 
Posner and Snyder proposed that the effects of context are due to two distinct mechanisms: a very fast spreading-activation component and a slower acting attentional component. The spreading-activation component does not require attentional resources and leads only to facilitation of related items, not to inhibition of unrelated ones. The attentional component interferes with ongoing activities that require attention, and it leads to inhibition of unrelated words. According to Berg and Schade (1992), the reason for the incorporation of inhibition in comprehension models of lexical retrieval was mainly empirical. The availability of specific responses was reduced in certain unfavorable conditions as compared to a neutral condition, and delayed retrieval was rationalized in terms of the operation of an inhibitory mechanism. Foss notes that "models that account for priming via irradiation among elements in the mental lexicon must have a damping function, else the entire system would soon be awake; complete activation of the lexicon is no better than a situation in which all members are deep in semantic slumber" (Foss, 1982:593). With the advent of connectionist frameworks in the 1980's, the concept of inhibition is conceived as a function of activation and of linkage strength: the more activation a node has accumulated, the more inhibition it sends out to its competitors (McClelland (1985)). It seems, thus, that the existence and usefulness of inhibition is no longer questioned in studies of human memory. As Berg and Schade put it, "the real challenge is rather to identify the multifarious conditions under which facilitatory as opposed to inhibitory processes predominate"( Berg and Schade, 1992: 406).

\section{PRIMING MEMORY IN SENTENCE PROCESSING}

Foss (1982) discusses the decay of semantic facilitation in word lists and over the level of sentence and discourse. He reasons that models of semantic priming that focus on the activation properties of the lexicon seem to bear very little on sentence comprehension. Foss argues that there is experimental evidence showing that the priming effect found in lists of words is short lived, that is, if one or more words intervene between the priming word and the critical test item, no facilitation is found (Gough, Alford, and Holley-Wilcox (1981)). Since it is relatively rare that two semantically related items occur immediately adjacent to one another in sentences, models of priming based on word lists can predict very little priming during actual sentence processing. Foss proposes that the natural place to look for an alternative model is in the realm of discourse models. When an individual comprehends language, he or she is constructing and updating a semantic model representing elements and relations in the world of the speaker. Certain entities or propositions are likely to be the core or high level representation of the internal model. Foss assumes that these high level propositions in the semantic model being constructed remain active as long as the topic of the talk or story remains the same. 
If the ideas outlined above are true, one should not expect any significant facilitation decay in sentences as long as the later word being tested is related to some important, topical concept that occurred earlier. Foss conducted three experiments in order to test these ideas, which he formulated in terms of a weak version and of a strong version. The weak version says that the decay rate for priming is slower in sentences than in lists. The strong version claims that there is no decay of priming in sentences when later material is semantically related to the high-level topic of the discourse. Experiments I and II addressed the weak version of the hypothesis. In experiment I, subjects were auditorilly presented to trials composed of two sentences and asked to perform a phoneme-monitoring task. In this task, subjects are required to understand a sentence at the same time that they must respond by pushing a button when they hear a specified word-initial target phoneme. Reaction times to respond to the target is taken as a measure of local processing difficulty at the point where the target occurs. The first sentence in experiment I contained a pair of words that were semantically related to a critical noun of interest which occurred in the second sentence. There was a distance of 10 to 16 words between the words in the first sentence and the critical word in the second sentence. Experiment II was similar to experiment I with the crucial difference that it presented lists of words rather than sentences to the subjects. The results of these experiments were consistent with the weaker hypothesis outlined above: semantic facilitation is long lived in sentences and not in lists. In experiment I Foss found evidence that the presence of words semantically related to a critical word fastens the comprehension of that word even when the semantically associated items occur much earlier in a separate sentence than the critical word. In Experiment II, Foss reports that he found no evidence for processing facilitation of the critical noun when semantically related words occurred earlier in the list. In his third experiment, Foss tested the strong hypothesis that in sentences the effects of semantic relatedness on processing a later item do not diminish with the distance between the associated items. Again subjects were asked to perform a phoneme-monitoring task in sentences and lists of words. Similarly to experiments I and II, both in the sentence and in the lists there was a relationship between two context words and a third, critical word. These items were semantically related or semantically more neutral. A crucial variable in experiment III was the distance between the context and critical words: the pair of context words occurred either close to the critical word (the near condition) or there were an average of 12 intervening words between them (the far condition). Foss reports that processing of the critical word was significantly faster in both the near and the far sentence cases when related words occurred than when neutral words occurred. More importantly, Foss found that the RT difference (neutralrelated) was basically the same for the far sentences as for the near sentences, but no facilitation was found for the far list case. These results confirmed his strong hypotesis, namely the idea that there is no decay of priming in sentences when later material is semantically related to the high-level topic of the discourse. 


\subsection{The processing of coreference in sentence comprehension}

The comprehension of anaphoric relations is an essential feature of human sentence. The basic processing issues concerning coreference assignment revolve around the questions of if, when and how the correct coreferential relationships are established among elements in a sentence. Typically the focus of the research has centered on the ability of referentially-dependent elements such as overt pronouns and empty categories to facilitate the comprehension of a previously mentioned noun phrase (NP), or antecedent. A number of recent studies in Psycholinguistics have shown the processing relevance of empty categories and pronouns in English. That is to say, these elements have been shown to be psychologically real in the sense that they trigger a reactivation ${ }^{2}$ of their antecedents.

Chang (1980) conducted experiments that demonstrated that recognition responses for a person's name were significantly faster when a final clause contained a pronoun referring to the person than when it did not. Corbett and Chang (1983) showed further that all previously mentioned NP's - antecedents as well as nonantecedents - get reactivated by a pronoun. Subjects read sentences such as "Jack threw a snowball at Phil, but he missed" and were presented a probe word immediately following each sentence. Results indicated that both the antecedent and the nonantecedent of "he", the NP's "Phil" and "Jack" were reactivated by the pronoun.

Cowart and Cairns (1987) showed that the initial assignment of an antecedent to a pronoun obeys structural constraints, but not constraints on semantic or pragmatic wellformedness. Their experiments suggests that a pronoun triggers all and only those prior referents that are structurally appropriate as the antecedent. They argue that there is a device that computes coreference, and that this device has access to structural information, but not to what is often considered to be "higher level" information, such as semantics and pragmatics.

Several studies have also been conducted in order to assess whether similar effects could be established for antecedents of different types of empty categories. For example, Bever \& McElree (1988) have found evidence that gaps access their antecedents during comprehension in the same way as overt pronouns and that gaps produced through movement access their antecedents more strongly than the null pronominal PRO. MacDonald (1989) conducted a study in which NP-traces are shown to unequivocally prime their antecedents in passive constructions in English. Gap and non-gap conditions differed by only one word, ruling out the possibility that differences in reaction times could be attributed to differences in the processing loads.

Swinney, Ford, and Bresnan (1988) used a cross-modal priming paradigm in order to show that a phonetically null NP may trigger immediate reactivation of its antecedent. For

2 According to Fodor (1989) "reactivation" may a matter of excitation of the relevant in the mental lexicon or of the relevant concept in the representation being contructed for the sentence 
example, there is a trace following the embedded verb in a sentence such as, the policeman saw the boy that the crowd at the party accused [ $t$ ] of the crime. Associates of boy and crowd as well as unrelated words matched in length and frequency to the associates were probed at different points in the sentence: 1) after party; 2) after accused; and 3) 300 ms downstream from point (2). The level of activation of the antecedent of the antecedent of the trace, that is, boy, was found to be greatest at point (2), exactly where a trace would be represented.

\subsection{The types of information available to the processor}

Besides answering the question concerning the perceptual reality of coreference assignment, the research on the processing of gaps has also been particularly informative with respect to the questions of decision principles and constraints on information use in the comprehension of sentences. As a matter of fact much of the recent research on sentence understanding has focused on identifying the types of information available to the sentence processor or parser during comprehension (see Fodor, 1989, for a detailed review). In this brief review we are going to concentrate on two issues which are of particular relevance for the purposes of the present study: the use of subcategorization information in processing and the so-called "most recent filler strategy" (MRFS) proposed by Frazier, Clifton \& Randall (1983).

Two views about the type of information accessed during comprehension have dominated the literature. According to one position, the parser rapidly builds a syntactic skeleton by making use of phrase structure rules and simple decision principles such as the minimal attachment principle, by means of which "incoming material is attached into the phrase marker being constructed using the fewest nodes consistent with the well-formedness rules of the language" (Frazier, 1979; 76). As in such a system, syntactic category information is the primary input and other sources of information are basically ignored, many mistakes usually arise in the form of the so-called "garden-path" phenomenon. For example, in parsing a sentence such as "The horse raced past the barn fell", the processor commits itself to the simplest tree and when it gets to "...fell" it is garden-pathed and has to backtrack in order to revise the analysis. On this view, combinatory lexical information such as subcategorization information can only be used in reanalysis after the parser's original analysis fails (Ferreira \& Clifton, 1986).

Another view proposes that the comprehension system rapidly and optimally integrates lexical, syntactic and contextual information in some form of mental representation. In such a system, the immediate access to argument and control structure information allows the parser to project structure and avoid indeterminacy (Crain \& Steedman, 1985).

Argument-structure information is any information concerning the types of immediate complements a word may take. Syntactic subcategorization is a specification of the types of constituents that can serve as complements of a lexical item. According to Frazier et al. (1983), subcategorization information is not available to the parser in the initial stages of syntactic processing. In order to demonstrate their point, these authors compare the processing times of sentences exhibiting long-distance filler-gap dependencies, such as: 
(1) "This is the girl-i the teacher-j wanted [e]-j to talk to [e]-i"

(2) "This is the girl-i the teacher- $j$ wanted [e]-i to talk

(3) "This is the girl-i the teacher-j decided [e]-j to talk to [e]-i"

(4) "This is the girl-i the teacher-j forced [e]-i to talk"

At issue here is how the sentence processor decides which filler to associate with which gap. Frazier et al proposed the Most Recent Filler Strategy, by means of which gaps are coindexed with the most recent potential filler, Thus (2) should be harder to process than (1), since in (2) the coindexation with the most recent filler would turn out to be wrong and would have to be revised later, consuming processing time. Frazier et al considered that syntactic subcategorization information was not accessed at this early stage, since (4) was still harder than (3) regardless of the different control properties of the verbs "decided" and "forced".

Frazier, Clifton and Randall (1983) also cite developmental data in support of the Most Recent Filler Strategy: young children have been observed to interpret the most recent filler as antecedent of PRO in sentences containing "subject control verbs" such as promise in "Mary promised Sue PRO to get the book", as well as in sentences presenting "object control verbs", such as in "Mary told Sue PRO to get the book".

In keeping with the idea of a parsing system in which syntactic category information constitutes the primary source of information, Clifton \& Frazier (1989) also proposed the "active filler hypothesis", according to which a gap would be postulated on the basis of antecedent information well before the verb subcategorization could be accessed. Clifton \& Frazier propose that as long as it has an unassigned filler in a nonargument position, the parser prefers to posit a gap for the filler rather than take into consideration the lexical properties of the head of the phrase. If subcategorization information about the verb is inconsistent with the postulation of the gap, the hypothesized gap is deleted.

Notice, however, that the question whether lexical information can be accessed in the initial stages of the parsing process is far from settled. For example, Boland, Tanenhaus and Garnsey (1988) arrived at a different conclusion using sentences such as:

(5) which frog/snake did the girl force

(6) The girl forced the frog/snake to hop past the rock

Using a self-paced reading task, the authors found that readers were able to detect the incongruity of a snake hopping immediately at the verb "hop", demonstrating that the control properties of the object control verb force have been used immediately either in whsentences or in non-wh sentences. Additionally, several types of on-line processing evidence have also made a strong case that combinatory lexical information is immediately used in parsing (e.g. Stowe, 1989; Tannenhaus, Stowe \& Carlson, 1985; Tannenhaus \& Carlson, 1989; Tyler, 1989) 
Additionally, Nicol and Osterhout (1990) tested the MRFS during sentence comprehension. Using a cross-modal lexical priming technique to provide an on-line measure of activation of previously mentioned nouns, they found no evidence that the MRFS is invoked during sentence processing. Nicol and Osterhout used sentences such as the following pair:

(7) That's the actress-i that the dentist-j from the new medical center in town...

a) had invited t-i PRO-i to go to the party

b) had declined PRO-j to go to the party with $t-i$

Subjects were asked to make a lexical decision at the probe point to either a word or a nonword which appeared on the CRT screen. The hypothesis that the MRFS operated during sentence processing would predict priming for items related to the most recent filler and not the distant filler - in both sentence types. However, Nicol and Osterhout found out that the most recent filler is only weakly primed, and only in the sentential context in which it is the correct antecedent of PRO. Based on these results Nicol and Osterhout argue that a strategy such as the MRFS is unnecessary for parsing sentences containing PRO .

In sum, Tannenhaus et alii studies of filler-gap sentences provide evidence that the language processor has rapid access to both argument structure and control information. Such results complement an increasing body of research demonstrating that lexical information may play an immediate role in guiding parsing decisions.

In the next section, we present evidence in favor of the processing relevance of gaps which refer to topics (A'-bound gaps) in BP. As it will be argued, our data also seems to confirm that subcategorization information is indeed accessed by the parser at early stages of comprehension. We also argue that experimental methodologies such as the priming technique can be extremely useful because they allow us to have an assessment of our data which reflects not only conscious judgments on the part of the speakers. Such methodologies which can also tap on-line or automatic processes beyond the speaker's awareness or intention are relevant in linguistic research not only because they allow us to investigate the types of information which are immediately accessed by the human parser during comprehension, but also because they offer an objective measure to improve the reliability of the data.

\section{THE COMPREHENSION OF OBJECT ANAPHORA IN BRAZILIAN PORTUGUESE}

In this section we examine the comprehension of the empty category and the third person overt lexical pronoun in object position in Brazilian Portuguese (BP). The results of a psycholinguistic experiment show that the processing of BP overt and nonovert 
objects is consistent with the leading idea underlying the Overt Pronoun Constraint (OPC) proposed by Montalbetti (84): in languages which allow a choice between an overt pronoun and an empty category, the overt pronoun specializes for the coreferential reading and the empty category for the bound reading. The experiment used a probe recognition task in which the target sentences were auditorily presented to subjects and reaction times to visual probes corresponding to the antecedent of the pronoun and of the gap were measured. Results from 48 adult native speakers of Brazilian Portuguese indicate reactivation of the antecedents only by topic-bound gaps, which exhibit a stronger priming effect than subject-bound gaps, and by subject-bound overt pronouns, which show a stronger facilitation effect than topicbound overt pronouns.. Based on these experimental results, we suggest that overt pronouns and gaps in object position adopt distinct types of anaphoric recoverability strategies. Additionally, we claim our experiment to be informative with relation to several theoretical psycholinguistic issues: the psychological reality of gaps, the role of grammatical structure in the priming process, the most recent filling strategy, the effect of the global topic of discourse in reference resolution, the rapid access by the human parser to information on the argument frames of predicates.

\subsection{Method}

In this section we describe the participants, the materials and design as well as the testing procedures used in the experiment, which was conducted by the author in the Psycholinguistics laboratory of the University of Southern California in 1993.

\subsubsection{Subjects}

Forty-eight (48) USC, UCLA and UC Berkeley brazilian undergraduate and graduate students participated in this experiment. All were native speakers of brazilian portuguese with normal or corrected vision and normal hearing.

\subsubsection{Materials and design}

The stimuli were 12 sets of 60 sentences. Each subject was presented one of these experimental sets embedded in an extra set of 60 filler sentences. Each experimental set was made up of 6 experimental conditions and 6 control conditions with five sentences per condition in a $3 \times 2 \times 2$ type of design. There were two levels of matrix (topic/subject), three levels of subordinate clauses (gapless, overt pronoun, empty category), and two levels of probe (antecedent, other). Table 1 provides an example of each of the experimental conditions tested in the experiment. The control conditions were the same as the experimental condi- 
tions except that a probe other than the antecedent of the overt pronoun or gap was presented. This other probe was the subject of the matrix clause in the case of the topic sentences and the subject of the embedded clause in the case of the subject sentences. Notice that although sentences were very similar, differing only in terms of the tested variables, they were distributed between subjects, so that each subject saw only one version of each sentence type. The distribution of sentence types in 12 sets allowed all sentences of a type to be compared. To provide a counterbalance for the extra NP required in the topic sentences, all subject sentences had an extra PP in the matrix clause in order to try to rule out the possibility that differences in reaction times could be caused by different processing loads rather than by the experimental factors .

\section{Table 1}

(1) Subject-bound null object

A moradora-i disse agora mesmo na entrevista à televisão que os bombeiros já estão ajudando [e]-i

"The resident said right now in the interview to the television that the firemen are already helping"

(2) Subject-bound overt pronoun

A moradora-i disse agora mesmo na entrevista à televisão que os bombeiros já estão ajudando ela-i

"The resident said right now in the interview to the television that the firemen are already helping her"

(3) Gapless subject structure

A moradora disse agora mesmo na entrevista à televisão que os bombeiros já estão chegando. "The resident said right now in the interview to the television that the firemen are already arriving."

(4) Topic-bound null object

Os desabrigados-i, a moradora disse agora mesmo na entrevista que os bombeiros já estão ajudando $[\mathrm{e}]-\mathrm{i}$ 
"The homeless, the resident said right now in the interview that the firemen are already helping."

(5) Topic-bound pronoun

Os desabrigados-i, a moradora disse agora mesmo na entrevista que os bombeiros já estão ajudando eles-i

"The homeless, the resident said right now in the interview that the firemen are already helping them."

(6) Gapless topic structure

Os desabrigados, a moradora disse agora mesmo na entrevista que os bombeiros já estão chegando.

"The homeless, the resident said right now in the interview that the firemen are already arriving."

\subsubsection{Procedures}

The study used a cross-modal priming technique. Subjects were given a probe recognition task in which target sentences were orally presented and reaction times to visual probes corresponding to the antecedent of the overt pronoun and of the gap were measured in the case of the experimental sentences. For the control sentences, we measured reaction times to visual probes corresponding to the subject of the matrix clause in the case of the topic sentences and to the subject of the embedded clause in the case of the subject sentences.

Subjects indicated whether or not the probe word had occurred anywhere in the sentence by pressing a yes or a no key in a button box. This response removed the probe and presented a comprehension question on the screen which should also be answered by pressing a yes or a no key in the button box. Following three practice trials, experimental, control and filler sentences were presented in a different random order to each participant. Subjects were tested individually in sessions of approximately 25 to 30 minutes and generally reported in post-session interviews that the task was at least moderately easy.

\subsection{Results}

The logic of the experiment was as follows. A consistent finding of recent studies on coreference processing is that reference-dependent sentential elements seem to trigger reactivation of the antecedent NP's to which they refer. This reactivation or "priming effect" 
of overt and implicit anaphoric elements has been found both in studies which checked for on-line probe recognition and in studies which use end-of-sentence probes as it is the case in our experiment. By recording and comparing reaction times to the experimental and control sentences across the 6 conditions we expected to assess whether pronouns and empty categories in object position in BP would facilitate the access to their antecedents and whether this facilitation effect would vary with relation to the subject/ topic nature of the antecedent. The extent to which the reactivation of subjects and topics by the empty and by the overt anaphors varied with relation to the gapless conditions is shown in Figure 1. The gapless condition may be taken as a baseline in order to ascertain whether or not the presence of structural constraints will affect comprehension. The configuration in Figure 1 indicates that there are no significant differences between the processing times for the gapless topic and subject constructions. No matter how the human sentence processor copes with topic structures, the final results for the BP data show that comprehenders deal with topic-comment relations as fast as they deal with subject-predicate relations. This finding provides interesting processing evidence in favor of the claim that BP is a language in which topic/comment relations are as prominent as subject/predicate relations.

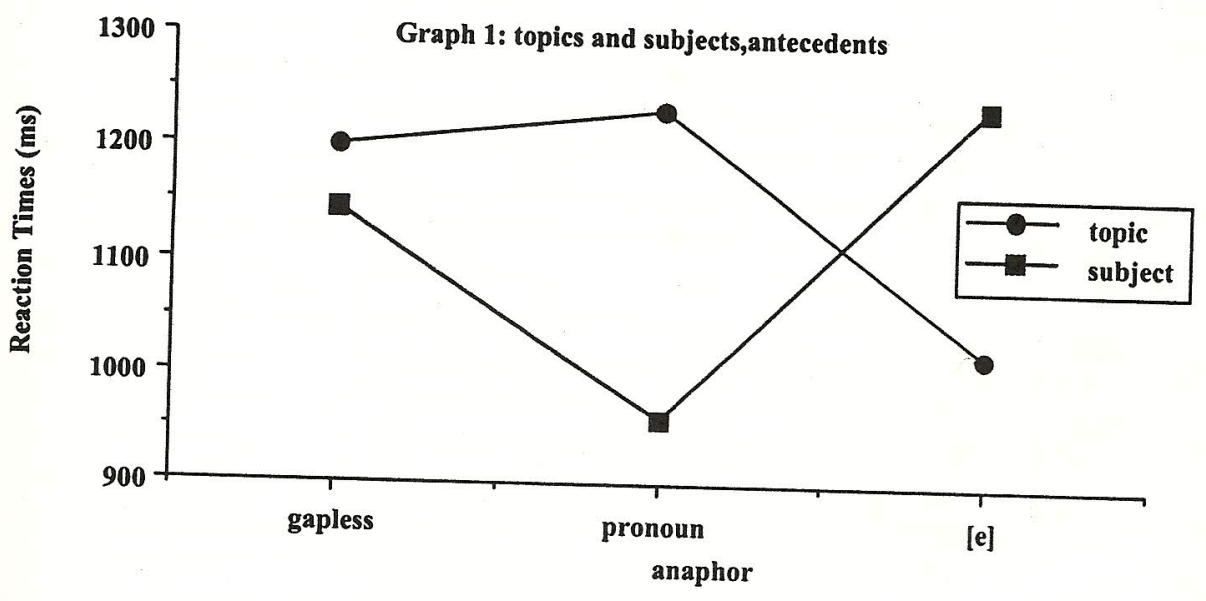

Figure 1: Topics and Subjects as antecedents

Our data show a stronger priming effect for the gap coindexed with the topic (the A'-bound gap) than for the gap coindexed with the subject (A-bound gap) and stronger priming effects for the overt pronoun coindexed with the subject than for the overt pronoun 
coindexed with the topic. In the topic sentences, reaction times to the antecedent probe were 180 milliseconds faster in the gap condition than the gapless condition, $[F(1,48)=12.07$, $p<.05]$. In the case of the subject sentences, response times to the antecedent probe were 187 milliseconds faster in the pronoun condition than the gapless condition, $[F(1,48)=$ $10.06, \mathrm{p}<.05]$. These are clearly significant statistical results, showing an interaction between sentence type and anaphor. In sum, Experiment 1 provides evidence that antecedents in A-position have a preference for overt anaphoric elements, whereas elements in A'-position prefer to be coindexed with empty categories.

Figures 2 and 3 allow us to compare results for antecedent probe with results for probes of other NPs in the sentences. Remember that in topic sentences, the "other" probe corresponds to the subject of the matrix. Thus, as it is clear in figure 2 (top antecedent/other), subjects display overall slower RT's when they are processed in topic sentences. In the gap sentences, it would be legitimate to conceive of an interpretation along the lines of the gapless topic cases, in which the subject, not the topic, would be the antecedent for the gap. In such an interpretation, the topic would be in a "dangling" position, as in the gapless topic cases, just setting the framework of reference in which the comment would hold. Thus in a sentence such as (4) in TABLE 1, the subject a moradora "the resident" could be thought of as the binder of the null object. Our results, however, show that this is not the favored interpretation, since RT's for the recognition of topic antecedents are faster than RT's for the recognition of subject antecedents in the same sentence.

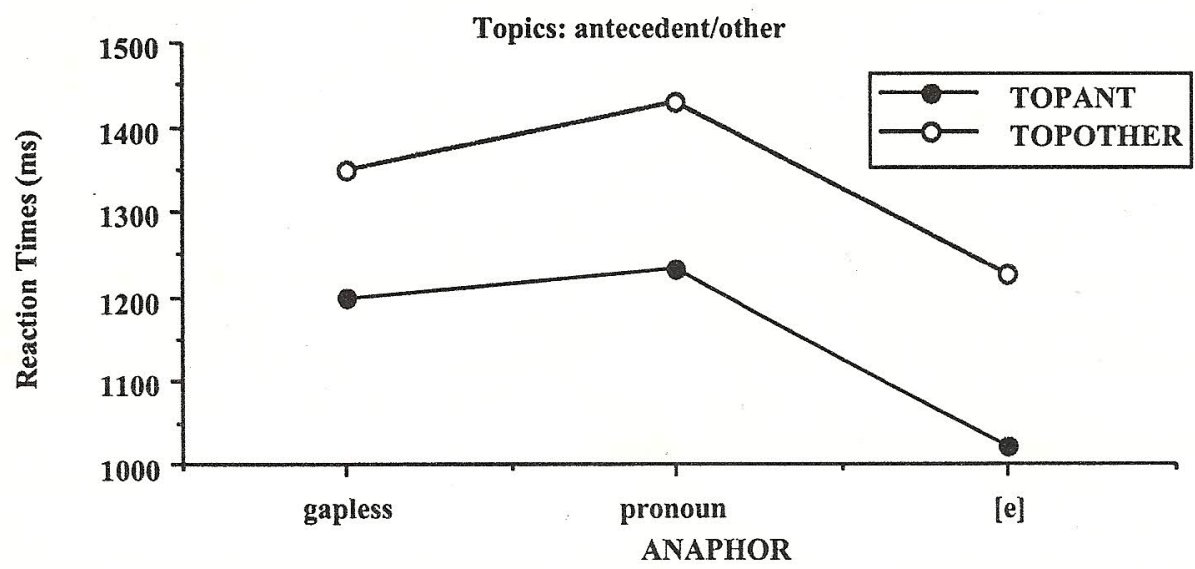

Figure 2: Topics, antecedent/other 


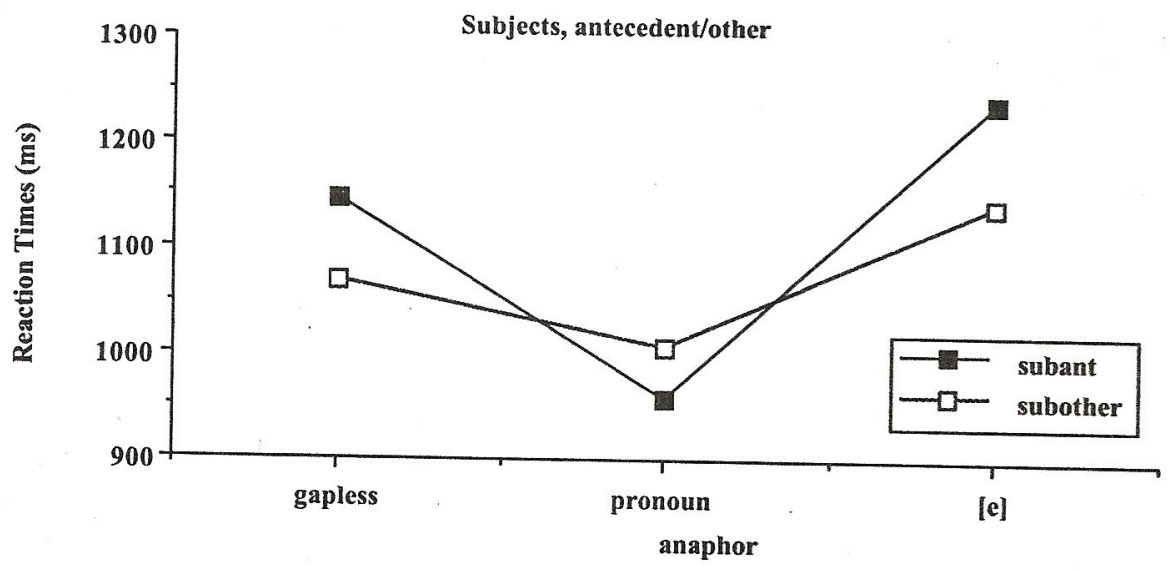

Figure 3: Subjects, antecedent/other

Now if we compare RT's for the gap case with RT's for the overt pronoun case, we notice a difference of $202 \mathrm{~ms}$ between them. As there was a systematic mismatch of gender and/or number between subjects and topics in these sentences, the overt pronoun, which matched in features with the topic, made the recognition of the subject even slower than the gapless case (see table II).

TABLE II. Recognition Latencies (in $\mathrm{ms}$ )

\begin{tabular}{|l|l|l|}
\cline { 2 - 3 } \multicolumn{1}{c|}{} & $\begin{array}{l}\text { SUBJET } \\
\text { antecedent/other }\end{array}$ & $\begin{array}{l}\text { TOPIC } \\
\text { antecedent/other }\end{array}$ \\
\hline gapless & $1146 / 1070$ & $1200 / 1351$ \\
pronoun & $959 / 1007$ & $1235 / 1430$ \\
null & $1239 / 1140$ & $1020 / 1228$ \\
\hline
\end{tabular}

In the subject sentences the "other" probe was identical to the subject of the embedded clause, which was very close to the probe point. As Figure 3 shows, an expected recency effect obtained here: recognition of embedded subjects in gapless clauses was faster than recognition of matrix subjects due to the proximity between the former and the probe 
point. Nonetheless, notice that gaps still keep the same "delay effect" when compared to pronouns that was displayed in the matrix subject antecedent cases. Regardless of the systematic mismatch in gender and/or number between the subject of the matrix and the subject of the embedded clause, overt pronouns still seem to display a stronger tendency than gaps to facilitate recognition of elements in A-position.

\subsection{Discussion}

\subsubsection{Subcategorization Information}

An important issue in Sentence Processing has been whether the language processor has rapid access to argument structure in parsing. Another related issue concerns the positing of gaps based on antecedent information. Clifton and Frazier (1989) claim that gaps are posited as a first resort, that is, the parser makes use of antecedent information in order to decide whether or not to hypothesize a gap in a sentence. Our results suggest that the parser has immediate access to subcategorization information and that a gap does not seem to be posited on the basis of antecedent information. Notice that RT's to the gapless cases are not significantly different. That is, subject/predicate relations seem to be handled as readily as topic/comment relations. However, if the parser were to posit a gap as a first resort it would be legitimate to expect that gapless topic sentences should take longer to process than gapless subject sentences since only in the topic case a gap would be mistakenly posited. If these BP sentences were parsed according to the Active filler hypothesis (Clifton \& Frazier(1989), the processor should postulate an empty category right after it identified a filler in nonargument position, in our case the topic. However, by pursuing such a strategy, the processor would be garden-pathed because the positing of a gap would be wrong in this case, since the verb in the embedded clause is intransitive and projects no empty category. Both the positing of the gap and the "surprise" reaction by the processor should presumably take processing time. However this is not the case in our data, since as we have showed above there is no significant difference between the processing times for the topic and the subject gapless sentences.

On the other hand, it seems clear in our data that subcategorization information guides the parser in the processing of long distance dependencies. Note that experimental sentences such as (4) in which there is a transitive verb in the embedded clause, display a clear priming effect of their antecedents in topic position when compared to the gapless topic sentences discussed above. This happens presumably due to the fact that the processor uses the information about the argument structure of the verb in order to postulate the gap and then associate it with the filler in topic position. In the gapless cases there is no empty category to be postulated, once the verbs in the embedded clause are intransitive. Since there is no gap to reactivate the antecedent, RT's are longer in the gapless case than in the gap case. 
Therefore, our results provide additional evidence in favor of an "optimal" model of parsing, that is, a comprehension system which has access not only to syntactic category information, but also to other types of information, such as argument structure.

Our results also provide evidence that favor an interpretation of the most recent filler strategy in terms of the "salience" strategy rather than in terms of recency (Frazier, Clifton \& Randall (1983)). As displayed in Figure 2 (top ant/other) the filler which is more readily associated to the gap in experimental sentences such as (4) in Table 1 is the topic and not the subject (the "other" probe), even though the subject is the most recent potential filler. These results suggest that the processor probably assigns the most salient filler to the gap, not necessarily the most recent. In the case of topic sentences in BP, the processor might be using cues such as the particular intonation and stress patterns which signal that a phrase is in topic position, in order to establish the coindexation between that phrase and the gap.

\subsubsection{The architecture of the human sentence processing mechanism}

Therefore, according to our data, topics do not seem to function as active fillers and the postulation of a gap is not triggered by the antecedent in $A^{\prime}$-position. If this is the case, what is the architecture of the human sentence processing mechanism (HSPM) that could account for the BP facts presented above? We want to speculate that the HSPM deals with the fragment of BP grammar presented above in the following manner. First the HSPM constructs a surface structure representation of the sentences, left to right. In the case of the topic sentences, the topic phrase is represented in a nonargument position. In the subject sentences this position is left empty. As we have argued above, the parser has access to information concerning subcategorization properties of predicates. Therefore upon encountering a transitive verb the parser expects an object. If there is not an overt object, a gap is postulated and coindexation with an antecedent must take place. As suggested by Nicol (1988), the assignment of coreference is carried on by a coreference module which constitutes an intermediate stage between purely structural processes and interpretive processes. This coreference device must determine which referents are potential antecedents of a referentially-dependent item in order to access those referents. In the light of the results we obtained in the experiment, we propose that such a coreference device must have access to information concerning argument/nonargument positions in the following way. If the parser encounters a pronoun after the verb, the coreference device will search first for an antecedent in argument position. If there is not a suitable antecedent in argument position, then a referent must be found in discourse or in the pragmatic context. The crucial fact that is clear from our results is that object overt pronouns in BP "prefer" antecedents in argument position. As a default strategy, the coreference device looks for an antecedent for the pronoun at the sentence level as a first resort. If there is not one antecedent available at this level, then nonargument posi- 
tions will be checked. Now, what happens if the processor finds a gap after the verb instead of a pronoun? In that case, as it is clear from our data, the coreference device will look for an antecedent in a nonargument position as the best candidate for coindexation with the gap. Thus, in the same way as an overt object pronoun triggers the search for an antecedent within the sentence level, object gaps look for their antecedents outside the scope of the sentence, in a peripheral position ( $A^{\prime}$-position) or even in the context of utterance. In the remnant paragraphs of this section, we attempt to speculate on possible cognitive reasons for this processing difference between subjects and topics.

In the topic-comment type of packaging (Chafe 1976), the speaker seems to recall a concept which is then commented on. In the subject-predicate type of packaging, the speaker seems to be also recalling an event or concept, however this informational item is immediately integrated into a proposition. At the syntactic level, procedures such as GF assignment, $\phi$-role assignment, case assignment, etc. are going to take place in order to license that NP in a well formed sentence. In the topic-comment strategy, on the other hand, the concept is established as a generic frame of reference, a set of potentialities of meaning which may or may not be precised through grammatical operations and processes at the Sentence level. This peripherical nature of the position allows the interface between pragmatics and discourse and the grammaticalities of the sentence. This is is the distinction that Chafe proposes between the topic as the psychological "subject" of the sentence and the subject as the proper grammatical "subject" of a sentence. When we hear a gapless topic sentence such as (6) in $\mathrm{BP}$ it does not seem that we have a surprise effect that would delay the comprehension of the topic sentence when we find out that the topic cannot be integrated at the sentence level with the proper GF's, $\varnothing$-roles, etc. In the production end, it seems that the speaker has an idea, but he does not know or want at this instant to make a predication on this idea that would take it as a specified argument of a proposition. Rather, he came up with this idea and he makes a comment on it without having necessarily to fit it into a specific structural slot. The concept sort of remains activated as "a psychological subject", a source of interpretive possibilities throughout the sentence. If there is a gap at the structural level to integrate the topic, a reactivation effect will happen, as we have demonstrated in the experiment. The speaker may refer back to this concept, by means of a gap, an overt pronoun or an NP which in BP may even be the same as the topic alluded to. If the hearer tried to integrate the topic at once, it would be licit to expect that the RT's for gapless topic sentences would be higher than RT's for equivalent "gapless" subject sentences, since as we have already noted, there would be a "surprise effect" for the former only. Topics are concepts which get lexicalized (or not, consider the possibility of null topics), but which have a minimum degree of grammaticalization. Notice the existence in BP of gapless topics, PP topics with chopped preposition, etc,. These facts become even clearer if we consider that topics seem to occur mostly in the flow 
of spontaneous and colloquial discourse and less in carefully planned and organized speech (Pontes, 1987). Therefore the best candidates for topic anaphora are empty categories, since these elements do not carry any definite inflectional markings, such as pronouns do. Even in terms of the content of their referents, they do not necessarily retrieve any specific and definite entity, since they can always have an arbitrary or pragmatic interpretation. It is thus legitimate to suppose that gaps are more natural anaphoric means to retrieve topics than overt pronouns, since they do not commit themselves to inflectional features, such as pronouns do. Therefore, overt pronouns and gaps seem to differ in terms of their recoverability capacities. While pronouns will recover grammatical features such as gender, number, case etc., which have usually been grammaticalized in the subject position, gaps are simply structural slots, placeholders for antecedents. In other words, overt pronouns and gaps adopt distinct types of anaphoric strategies: whereas the overt pronoun requires the matching with certain grammatical features, gaps do not. Thus pronouns just go better with arguments, because these have already been adequately grammaticalized in the sentence and gaps are the best retrievers for topics, given their usual low degree of grammaticalization. Notice that this low level of grammaticalization of topics might even be a characteristic of their nonargument position, in which no case, $\varnothing$-roles or grammatical functions are assigned. It may also be the case that the preference for zeros as anaphoric devices to make reference to topics is an on-line processing strategy used by the language processor in production in order to avoid identificational errors which might arise as a result of mismatch of feature agreement.

It is interesting to note that this processing default strategy which we are proposing to account for the ability of zero anaphora to display higher levels of reactivation of its topic antecedent than the overt lexical pronoun actually provides a partial explanation for Givón's (1983) scale of phonological size. In a speaker-hearer neutral study of topic continuity in discourse Givón notes that zero anaphora is more used cross-linguistically as a grammatical device to identify topics than other other coding devices with increasing phonological size. Givón proposes that a basic principle of iconicity underlies this scale of phonological size: "the more disruptive, surprising, discontinuous or hard to process a topic is, the more coding material must be assigned to it" (p.18). In turn, Givón continues, this principle may translate into a more generic psychological principle: "expend only as much energy on a task as is required for its performance" (p.18). If the proposal we developed above is right, it provides a more straightforward psychological content for Givón's principles: gaps are better retrievers of topics than overt pronouns because they have different recoverability properties. In any case, regardless of how these facts are processed, the very observation that there are such differences in the anaphoric selectional properties of gaps and overt pronouns is a clear indication that even though both elements seem to behave syntactically as pronominals, they do have different interpretive properties. 
MAIA, Marcus. Language and priming memory

\subsection{Conclusion}

In summary, the experiment described above allows the following conclusions:

a) BP facts support the view that the human sentence comprehension mechanism is guided by structural considerations. There seems to be a processing distinction between subjects and topics which can possibly be related to elements which occupy argument position versus elements which occupy a nonargument position.

b) Topic bound object gaps in BP are psychologically real in the sense that they allow a faster reactivation of their antecedents. Subject-bound object gaps are either not psychologically real in BP or if real they are interpreted as arbitrary and do not allow a specific and definite interpretation.

c) Subcategorization information is rapidly accessed in BP sentence parsing. Unlike the prediction of the Active filler hypothesis (Frazier, 83), information about the predicate argument structure and not about the antecedent triggers the postulation of a gap in BP topic sentences.

d) When a topic and a subject compete in a sentence to be the antecedent of an implicit anaphoric element, the topic is the most readily element accessed by the gap, even though it is not the most recent possible filler.

e) A processing explanation is proposed in order to account for Givón's et alii (1983) crosslinguistic finding that zero anaphora is a more common grammatical device for the identification of topics in discourse than stressed/independent pronouns.

RESUMO: Este artigo discute o conceito de memória de reativação e seu uso em psicolinguística. Procede-se a uma revisão da literatura nas áreas de reconhecimento vocabular e de processamento de frases. Descreve-se e analisa-se um experimento psicolinguistico conduzido pelo autor a fim de investigar a compreensão dos objetos nulos em português brasileiro.

PALAVRAS-CHAVE: memória de reactivação, reconhecimento vocabular, processamento de frases, objeto nulo

\section{$\overline{\text { REFERENCES }}$}

ANDERSON, J.R. (1983) The Architecture of Cognition. Cambridge, MA: Harvard University Press.

AOUN, J. \& Y. Li. (1990) Two cases of Logical Relations: Bound Pronouns and anaphoric relations. ms., U.S.C., Los Angeles. 
BERG, T. \& SCHADE, U. (1992) The Role of Inhibition in a Spreading-Activation Model of Language Production.

I. The Psycholinguistic Perspective. Journal of Psycholinguistic Research, vol. 21, no. 6, 405-433.

BEVER, T. G. \& MCELREE, B. (1988). Empty categories access their antecedents during comprehension. Linguistic Inquiry, 19, 35-43.

BOLAND, J., TANENHAUS, M.K., \& GARNSEY, S.M. (1988). Evidence for the immediate use of verb control information in sentence processing, $\mathrm{ms}$.

CHAFE, W. (1976). Giveness, contrastiveness, definiteness, subjects, topics and point of view. In Li, C.N. Subject and Topic, New York: Academic Press.

CHANG, F.R. (1980) Active memory processes in visual sentence comprehension: Clause effects and pronominal reference. Memory and Cognition, 8, 58-64.

CLIFTON, C. \& FRAZIER, L. (1989). Comprehending sentences with long distance dependencies. In Greg N Carlson and Michael K. Tanenhaus (eds.), Linguistic Structure in Language Processing, Kluwer Academic Press.

CORBETT, A. T., \& CHANG, F. R. (1983). Pronoun disambiguation: Accessing potential antecedents. Memory and Cognition, 11, 283-294.

COWART, W. \& CAIRNS, H. (1987). Evidence for an anaphoric mechanism within syntactic processing: some reference relations defy semantic and pragmatic constraints. Memory and Cognition, 15, 318-331.

CRAIN, S. \& STEEDMAN, M. (1985). On not being led up the garden path: The use of context by the psychological parser. In D. Dowty, L. Kartunnen, \& A. Zwicky (Eds.), Natural Language Parsing. Cambridge: Cambridge University Press.

FERREIRA, F. \& CLIFTON, C. (1986). The independence of syntactic processing. Journal of Memory and Language, 25, 348-368.

FODOR, J. D. (1989). Empty categories in sentence processing. Language and Cognitive Processes, 4 (3/4) SI 155-209.

FOSS, D.J. (1982) A discourse on semantic priming. Cognitive Psychology 14, 590-607.

FRAZIER, L., CLIFTON, C., \& RANDALI, J. (1983). Filling gaps: Decision principles and structure in sentence comprehension. Cognition, 13, 187-222.

GIVON, T. (1983) Topic Continuity in Discourse: A Quantitative Cross-Language Study. Amsterdam/Philadelphia: John Benjamins Publishing Company.

KINTSCH, W. \& VIPOND, D. (1979). Reading comprehension and readability in educational practice and psychological theory. In L.G. Nilsson (Ed.), Perspectives on Memory Research. Hillsdale, NJ: Lawrence Erlbaum Associates. 
MAIA, Marcus. Language and priming memory

MACDONALD, M.C. (1989). Priming effects from gaps to antecedents. Language and Cognitive Processes, 4, 35-56.

MAIA, M. (1994). The comprehension of object anaphora in Brazilian Portuguese. Doctoral dissertation, ms., USC, Los Angeles.

MCCLELLAND, J.L., ST. JOHN, M. \& TARABAN, Roman.(1989). Sentence Comprehension:A Parallel Distributed Processing Approach. Language and Cognitive Processes, 4, (3/4)

MEYER, D.E. \& SCHVANEVELDT, R.W. (1971). Facilitation in recognizing pairs of words: Evidence of a dependence between retrieval operations. Journal of Experimental Psychology 90, 227-35.

MEYER, D.E. \& SCHVANEVELDT, R.W. \& RUDDY, M.G. (1974) Functions of graphemic and phonemic codes in visual word recognition. Memory and Cognition 2, 309-21.

MEYER, D.E. \& SCHVANEVELDT, R.W. \& RUDDY, M.G. (1975) Loci of Contextual Effects on Visual Word Recognition. In P.M.A. Rabbitt \& S. Dornic (Eds.), Attention and Performance V. New York: Academic Press.

MONTALBETTI, M. (1984). After Binding, Doctoral Dissertation, MIT, Cambridge, Massachusetts.

NEELY, J.H. (1977). Semantic Priming and retrieval from lexical memory: Roles of inhibitionless spreading activation and limited capacity attention. Journal of Experimental Psychology: General 106, 226-54.

NICOL, J. (1988). Coreference Processing during Sentence Comprehension. Doctoral Dissertation, M.I.T.

NICOL, J. \& OSTERHOUT, L. (1990). Reactivating Antecedents of Empty Categories during Sentence Processing. University of Arizona, ms.

PONTES, E. (1987). O tópico no Português do Brasil. Campinas, SP: Pontes.

POSNER, M.I. \& SNYDER, C.R.R. (1975). Facilitation and Inhibition in the processing of signals. In P. M. S. Rabbitt \& S. Dornic (Eds.), Attention \& Performance V. New York: Academic Press.

SINGER, M. (1990). Psychology of Language: an introduction to sentence and discourse processes. Lawrence Erlbaum Associates, New Jersey.

STOWE, L. (1989). Thematic structures and sentence comprehension. In Greg N. Carlson and Michael K. Tanenhaus(eds.), Linguistic Structure in Language Processing, Kluwer, Academic Press.

TANENHAUS, M., STOWE, L., \& CARLSON, G. (1985). The interaction of lexical expectation and pragmatics in parsing filler-gap constructions. In Proceedings of the Seventh Annual Cognitive Science Society Meetings, Lawrence Earlbaum Associates, 361-65.

TANENHAUS, M.K. \& CARLSON, G.N. (1989) Lexical structure and language comprehension. In W.D. MarslenWilson (Ed.), Lexical representation and process. Cambridge, MA: MIT Press. 
Revista da ANPOLL, n 2, p. 109-131, 1996

TULVIN, E. \& SCHACTER, D.L. (1990) Priming and Human Memory Systems. Science, vol.. 247, $301-306$.

TYLER, L.(1980) Serial and Interactive parallel theories of syntactic processing. MIT Center for Cognitive Science Occasional Paper 8. Cambridge, MA. 